\title{
Effects of lactoferrin on dexamethasone-induced osteoporosis in mice
}

\author{
Nobuo Izumo $^{1 *}$, Shinji Kagaya ${ }^{2}$, Masahiro Toho ${ }^{1}$, Megumi Furukawa $^{1}$, Yasuka Kabaya ${ }^{1}$, Takao Hirai ${ }^{3}$, Kohsuke Hayamizu ${ }^{1}$, Makoto Nakano ${ }^{1}$, \\ Tatsuo Hoshino ${ }^{2}$ and Yasuo Watanabe ${ }^{1}$ \\ ${ }^{1}$ General Health Medical Center, Yokohama University of Pharmacy, Yokohama, Japan \\ ${ }^{2}$ NRL Pharma, Inc., Kanagawa, Japan \\ ${ }^{3}$ Laboratory of Medicinal Resources, School of Pharmacy, Aichi Gakuin University, 1-100 Kusumoto-cho, Chikusa-ku, Nagoya, Aichi, Japan
}

\begin{abstract}
Glucocorticoids (GCs) have strong anti-inflammatory properties and are widely used to treat many inflammatory and autoimmune diseases. However, long-term GC therapy is limited by the associated serious side effects, such as osteoporosis. In the present study, we investigated the preventive effects of lactoferrin (LF) on dexamethasone (DEX)-induced bone loss in mice. Male ICR mice were treated with vehicle, DEX, or DEX and LF for 4 weeks. The femurs of all mice were analyzed using microcomputed tomography $(\mu \mathrm{CT})$. A number of indices, including bone mineral content $(\mathrm{BMC})$, bone volume, and bone mineral density (BMD), were significantly lower in the DEX-treated group than in the control group. Furthermore, lower BMC and BMD in the DEX-treated group were associated with impaired bone-related gene expression, as reflected by the weaker expression of Runx2, osterix (Osx), alkaline phosphatase (ALP), and osteopontin (OPN) than that in the control group. On the other hand, significantly higher total and cancellous BMD were observed in the LF-treated group than in the DEX-treated group. Furthermore, Osx and ALP gene expression was significantly stronger in the LF-treated group than in the DEX-treated group. These results suggest that the treatment with LF prevented DEX-induced osteoporosis in mice.
\end{abstract}

\begin{abstract}
Abbreviations: BMC-bone mineral content; BMD-bone mineral density; CT-computed tomography; DEX-dexamethasone; GC-Glucocorticoid; LF-Lactoferrin; Osx-Osterix; Runx2-Runt-related transcription factor 2
\end{abstract}

\section{Introduction}

Glucocorticoids (GCs) have strong anti-inflammatory properties and are widely used to treat chronic diseases, such as rheumatoid arthritis, asthma, inflammatory bowel disease, and collagen diseases [14]. However, long-term GC therapy is limited by the associated serious side effects, including diabetes, hyperlipidemia, and osteoporosis [57]. GC-induced osteoporosis is the most common form of secondary osteoporosis. The effects of exogenous GCs on bone have been well established [8-10]. GCs affect the function of osteoblasts, osteoclasts, and osteocytes [11]. Previous studies suggested that GCs also suppress bone formation by deregulating osteoblast function, including differentiation, proliferation, and apoptosis, leading to osteoporosis. Excess GCs induce osteoblast and osteocyte apoptosis by increasing pro-apoptotic molecules, reactive oxygen species, and endoplasmic reticulum stress [12].

Lactoferrin (LF) is an iron-binding glycoprotein that is synthesized and secreted by exocrine glands and specific granules of neutrophils $[13,14]$. After degranulation, neutrophils become the main source of LF in blood plasma. LF possesses various biological functions, including roles in iron metabolism, cell proliferation, and cell differentiation $[15,16]$. LF has also been identified as a potent anabolic factor affecting osteoblasts and osteoclasts. Recent findings suggest that LF is involved in the proliferation of osteoblasts, and attenuates apoptosis in osteoblasts $[17,18]$. In addition, LF has been shown to inhibit osteoclastogenesis and reduce bone resorption through an OPG/RANKL/RANK-independent mechanism [19]. A previous study suggested the potential of LF in the treatment of diseases such as osteoporosis [20,21].

We herein investigated the effects of LF on bone mineral content (BMC) in DEX-induced bone loss in mice in order to establish whether LF prevents GC-induced osteoporosis, which is the most common form of secondary osteoporosis. The results obtained suggest that the treatment with LF prevented DEX-induced bone loss, and this may be mediated, at least in part, by improvements in bone formation.

\section{Materials and methods}

\section{Materials}

Bovine LF was supplied by NRL Pharma, Inc. (Kanagawa, Japan). Dexamethasone sodium phosphate (DEX) was purchased from Wako Pure Chemical Industries, Ltd. (Osaka, Japan). All other chemicals were obtained commercially at the purest grade available.

\section{Animals and experimental procedures}

Forty-eight 7-week-old male ICR mice (Japan SLC Inc., Hamamatsu, Japan) were randomized by weight, assigned to groups, and acclimated to their cages for 1 week prior to the experiment. They were treated in accordance with the Guidelines for Animal Experiments at the Yokohama College of Pharmacy. Food and water

*Correspondence to: Nobuo Izumo, General Health Medical Center, Yokohama University of Pharmacy, 601 Matano-cho, Totsuka-ku, Yokohama 245-0066, Japan, E-mail: n.izumo@hamayaku.ac.jp

Key words: lactoferrin, bone mineral density, dexamethasone

Received: June 05, 2018; Accepted: June 21, 2018; Published: June 30, 2018 
were available ad libitum. Mice in each group were housed together under automatically controlled conditions of temperature $\left(24 \pm 1^{\circ} \mathrm{C}\right)$ and humidity (50 $\pm 10 \%)$. LF was dissolved at a concentration of $30 \mathrm{mg} /$ $\mathrm{mL}$ in water. In the first series of experiments, we examined the effects of LF on DEX-induced bone loss in mice. Eight-week-old mice were used in this experiment. Mice were divided into four groups and given DEX $(0.5 \mathrm{mg} / \mathrm{kg} /$ day, $\mathrm{n}=12)$, DEX and LF at $30 \mathrm{mg} / \mathrm{kg} /$ day $(L F 30, \mathrm{n}=$ 12), DEX and LF at $300 \mathrm{mg} / \mathrm{kg} /$ day (LF300, $\mathrm{n}=12$ ), or vehicle (saline, $\mathrm{n}=12$ ) by oral gavage once daily/7d/week for 4 weeks at a regular time. Body weight was measured weekly and the LF dose was adjusted accordingly. The second series of experiments were performed in order to evaluate the effects of LF on gene expression in DEX-induced bone loss in mice. At the end of the experiment, animals were euthanatized by an overdose of $\mathrm{CO}_{2}$. Femurs and tibiae were dissected for study.

\section{Bone densitometry and body composition analyses}

In a computed tomography (CT)-based analysis of bone mineral density (BMD), the tibiae (between the proximal and distal epiphyses) of 12-week-old mice were scanned at 1-mm intervals using an experimental animal CT system (LaTheta LCT-100; Hitachi Aloka, Tokyo, Japan). BMC (milligrams), bone volume (cubic centimeters), and BMD (milligrams per cubic centimeter) were calculated using LaTheta software (version 1.00). The minimum moment of inertia of cross-sectional areas (milligram-centimeter), which represents flexural rigidity, and the polar moment of inertia of cross-sectional areas (milligram-centimeters), which represents torsional rigidity, were calculated automatically by LaTheta software [22,23].

\section{MC3T3-E1 cell cultures}

MC3T3-E1 cells were purchased from the RIKEN Cell Bank. MC3T3-E1 cells were cultured in a-MEM (Life Technologies) containing $10 \% \mathrm{FBS}$ and $1 \%$ penicillin/streptomycin at $37^{\circ} \mathrm{C}$ in a $5 \%$ $\mathrm{CO}_{2}$ atmosphere. These cells were grown in non-supplemented medium until confluent (the first day of a confluent culture was referred to as day 0 ). On day 2 , cells were further cultured in $\alpha$-MEM containing $2 \%$ FBS medium supplemented with $10 \mathrm{mM} \beta$-glycerophosphate, $50 \mu \mathrm{g} / \mathrm{ml}$ ascorbic acid, and LF. Media were changed every 2-4 days [24].

\section{Measurements of nodule formation (NF)}

Cells were sonicated in $0.1 \mathrm{M}$ Tris buffer ( $\mathrm{pH} 7.2)$ containing $0.1 \%$ Triton X-100. NF was quantified by measuring the Ca content of the culture plate. Extracellular deposits were decalcified with 0.6 $\mathrm{N} \mathrm{HCl}$ for $24 \mathrm{~h}$. The Ca content of the supernatant was then assessed colorimetrically using the o-cresolphthalein complexone method with Calcium C-test Wako (Wako).

\section{RNA extraction and quantitative reverse transcription-PCR}

Total RNA was isolated using the ISOGEN RNA extraction kit (Nippon Gene) according to the manufacturer's instructions. cDNA synthesis was performed using the SuperScript VILO cDNA Synthesis Kit (Invitrogen). Real time-PCR was performed using the LightCycler 480 II system with the Universal Probe Library (Roche Applied Science) shown in Table 1. Gene assays were designed using Universal ProbeLibrary Assay Design Center software (Roche Applied Science). Reactions were performed in $20-\mu \mathrm{L}$ volumes and cycling conditions were $50^{\circ} \mathrm{C}$ for $2 \mathrm{~min}$ and $95^{\circ} \mathrm{C}$ for $10 \mathrm{~min}$, followed by 40 cycles of $95^{\circ} \mathrm{C}$ for $15 \mathrm{~s}$ and $60^{\circ} \mathrm{C}$ for $1 \mathrm{~min}$. Data are presented as relative mRNA levels calculated by the equation $2-\mathrm{Ct}(\mathrm{Ct}=\mathrm{Ct}$ of the target gene minus Ct of Gapdh). Roche LightCycler 480 software was used to perform an advanced relative quantification analysis of gene expression according to the LightCycler 480 instrument operator's manual.

\section{Data analysis}

Data are presented as the mean \pm standard error of the mean (S.E.M.). Differences in the mean values between each of the groups were analyzed by a one-way ANOVA followed by the Tukey-Kramer method of multiple comparisons. A value of $\mathrm{p}<0.05$ was considered to be significant. Statistical analyses were performed with STATVIEW 5.0 (SAS Institute).

\section{Results and Discussion}

In order to investigate whether LF contributes to the pathogenesis of bone loss in steroid-treated osteopenia, 8-week-old male ICR mice were treated daily with LF at $30 \mathrm{mg} / \mathrm{kg}$ or $300 \mathrm{mg} / \mathrm{kg}$ for 4 weeks in combination with DEX. Mice were weight matched before the DEX treatment. Body mass increased by approximately $25 \%$ in the untreated groups and decreased by $20 \%$ in the DEX and DEX plus LF groups during the four-week study period (Figure 1). The LF treatment did not result in any significant changes in body weight from that in the DEX-treated controls.

In order to investigate the effects of the systemic LF treatment on DEX-induced bone loss, we performed CT-based bone densitometry on DEX-induced trabecular bone loss with the oral administration of $\mathrm{LF}$ at 30 or $300 \mathrm{mg} / \mathrm{kg}$ or vehicle once daily/7d/week for 4 weeks starting on the day of administration of DEX. As shown in Figure 2A, BMC of the whole femur was significantly lower in DEX-treated mice than in untreated mice. In addition, BMD of the whole femur was significantly lower in DEX-treated mice than in saline-treated mice (Figure 2B). The simultaneous administration of LF to DEX-treated mice was more likely to prevent DEX-associated decreases in BMC of the femur (Figure 2A). The administration of LF significantly prevented DEX-associated decreases in BMD of the whole femur in a dose-dependent manner (Figure 2B). On the other hand, BMC and BMD of the cancellous and cortical bone of the femur were significantly lower in the DEX-treated group than in the control group (Figure $3 \& 4$ ). The oral administration of LF at 30 or $300 \mathrm{mg} / \mathrm{kg}$ to DEX-treated mice resulted in approximately

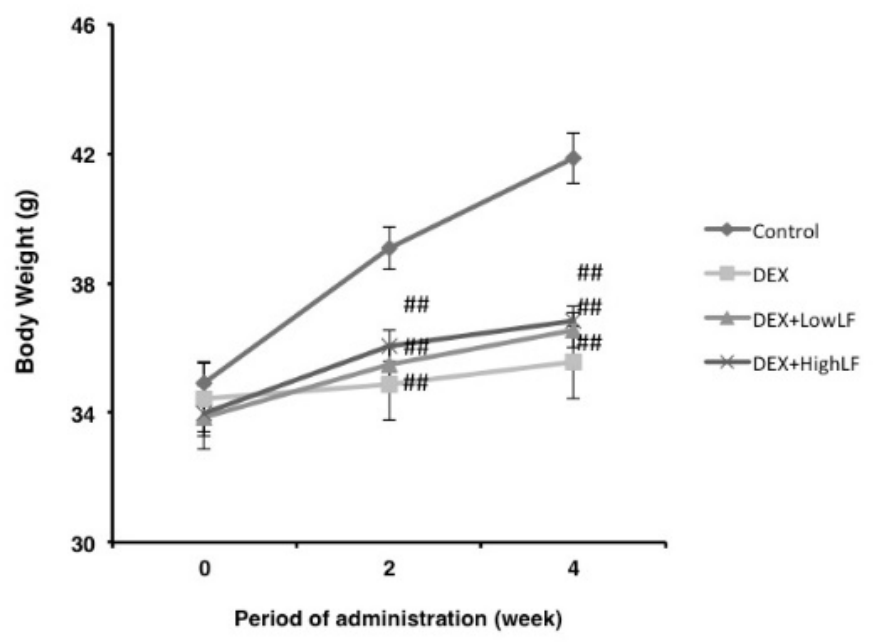

Figure 1. Effects on LF on body weight in mice.

Lines indicate the time course of weight changes in mice after 4 weeks of LF injections Mice were treated with DEX $(0.5 \mathrm{mg} / \mathrm{kg} /$ day, $\mathrm{n}=12)$, DEX and LF at $30 \mathrm{mg} / \mathrm{kg} / \mathrm{day}(\mathrm{LF} 30$ $\mathrm{n}=12)$, DEX and LF at $300 \mathrm{mg} / \mathrm{kg} /$ day $(L F 300, \mathrm{n}=12)$ or vehicle $(\mathrm{n}=12)$. \#\#: $\mathrm{p}<0.01$ significantly different from the control group. 
Table 1. Real time-PCR was performed using the LightCycler 480 II system with the Universal Probe Library (Roche Applied Science).

\begin{tabular}{|l|l|l|l|}
\hline Gene & $\begin{array}{l}\text { Universal } \\
\text { ProbeLibrary } \\
\text { Probe }\end{array}$ & Forward & Reverse \\
\hline GAPDH & $\# 9$ & AGCTTGTCATCAACGGGAAG & TTTGATGTTAGTGGGGTCTCG \\
\hline Runx2 & $\# 34$ & GCCCAGGCGTATTTCAGA & TGCCTGGCTCTTCTTACTGAG \\
\hline OPN & $\# 82$ & CCCGGTGAAAGTGACTGATT & TTCTTCAGAGGACACAGCATTC \\
\hline ALP & $\# 12$ & CGGATCCTGACCAAAAACC & TCATGATGTCCGTGGTCAAT \\
\hline Osterix & $\# 106$ & CTCCTGCAGGCAGTCCTC & GGGAAGGGTGGGTAGTCATT \\
\hline
\end{tabular}

A

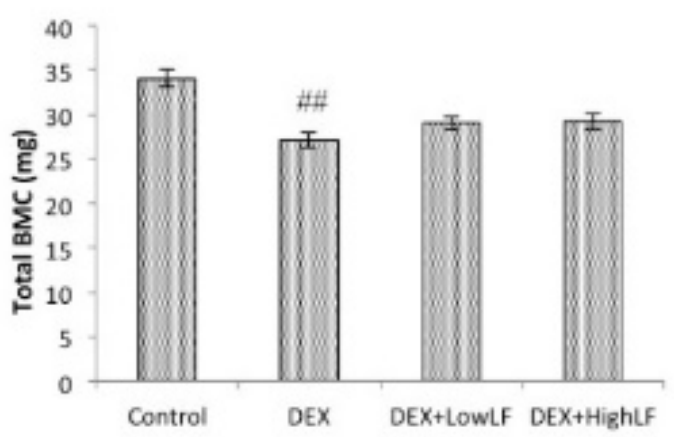

B

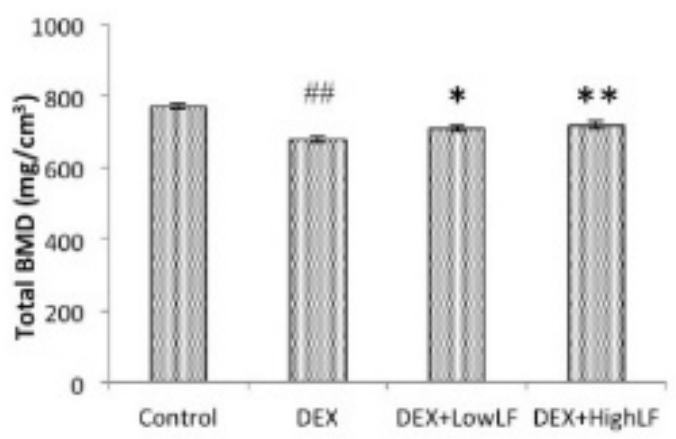

Figure 2. Effects of the administration of LF on total BMC and BMD in mice.

CT-based bone densitometry of the femurs of 12 -week-old male mice administered vehicle, $\mathrm{LF}$ at $30 \mathrm{mg} / \mathrm{kg} / \mathrm{day}$, or LF at $300 \mathrm{mg} / \mathrm{kg} / \mathrm{day}$ with or without DEX. Total BMC; A, total BMD; $\mathrm{B}$ calculated by LaTheta software. Values are expressed as means $\pm \mathrm{SEM} ; \mathrm{n}=12$ mice per group. \#\#, $P<0.01$ and $\#, P<0.05$ significantly different from the control group, $P<0.05$, significantly different from the DEX-treated group.

$10 \%$ higher BMC in the cancellous bone of the femur than in untreated mice; however, no significant changes were observed from the DEXtreated group. The effects of DEX were mostly prevented by the LF treatment because BMD in the cancellous bone of the femur was $10 \%$ higher in LF-treated mice than in DEX-treated mice (Figure 3). However, no significant differences were observed in the cortical BMC and BMD of the femur between saline- and LF-treated mice 4 weeks after the administration of DEX (Figure 4). In addition, we assessed the mRNA expression levels of osteoblast-related genes, including Runx2, Osterix (Osx), alkaline phosphatase (ALP), and osteopontin (OPN), in the distal end of the femur with the oral administration of LF at 300 $\mathrm{mg} / \mathrm{kg}$ or vehicle concomitant with DEX for 4 weeks. DEX decreased the expression levels of osteoblast-related genes, including Runx2, Osx, ALP, and OPN, in bone. Furthermore, the administration of LF to DEX-treated mice resulted in significantly higher expression levels of the Osx and ALP genes than the DEX treatment alone (Figure 5). These results suggest that the treatment with LF prevented DEX-induced bone loss by increasing bone formation.

In the present study, we reported that orally available LF significantly prevented DEX-induced bone loss in mice. The improvements observed in bone formation in DEX-induced bone loss with the LF treatment translated into higher BMC and BMD in mice. Furthermore, our results demonstrated that LF stimulated the differentiation and maturation of osteoblastic cells in vitro, which is consistent with the observation of increased osteoblast-related gene expression levels in bone following the LF treatment in vivo.

GCs potently suppress osteoblast activities and affect bone mineralization $[25,26]$. In addition, previous studies suggested that GC treatments impaired bone formation by inhibiting osteoblastogenesis [12]. The anabolic agent, hPTH (1-34), was found to be superior to bisphosphonates for increasing spine and hip BMD in GC-induced osteoporosis in both men and women [27-30]. Previous studies suggested that LF plays a role in modulating bone physiology. For example, LF prevented OVX-induced bone loss by mediating osteoblast and osteoclast functions [21]. On the other hand, LF has been shown to act as a potent anabolic factor in osteoblastic functions in vitro. In osteoblasts, LF stimulated ALP activity, osteocalcin secretion, and Runx2 phosphorylation, mainly by p38 signaling pathways [31]. Consistent with these findings, we also observed that LF increased the accumulation of $\mathrm{Ca}$ in a concentration-dependent manner in differentiated MC3T3-E1 cells (Figure 6). Therefore, the present results suggest that impaired bone formation with the decreased expression of OSX mRNA by DEX was due, at least in part, to a cellular dysfunction in osteoblasts. OSX is a key transcription factor required for osteoblast differentiation and bone formation. However, the exact mechanisms underlying the relationship between LF and the expression of osteoblast-related genes, including OSX, in osteoblasts remains to be elucidated in future studies.

\section{Conclusion}

In summary, we herein demonstrated that the oral administration of LF prevented DEX-associated cancellous bone loss in mice. These results indicate a potential use for LF in augmenting bone mass and preventing the adverse effects associated with GCs on trabecular bone, particularly through the regulation of bone formation.

\section{Funding}

Financial support was provided by NRL Pharma, Inc., Kawasaki, Japan. The funders had no role in study design, data collection and analysis, decision to publish, or preparation of the manuscript. 
A

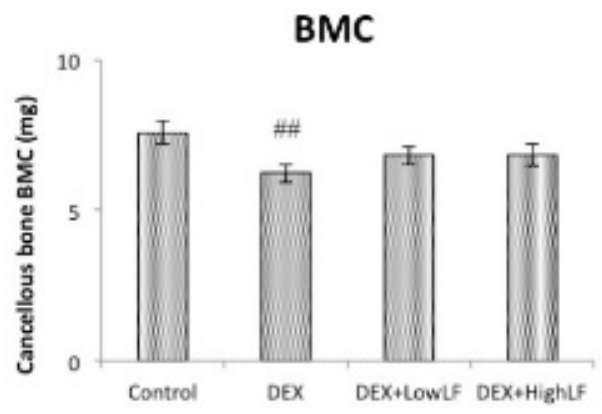

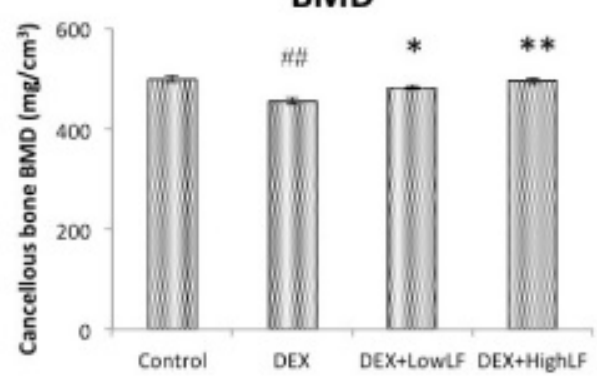

Figure 3. Effects of the administration of LF on cancellous BMC and BMD in mice.

CT-based bone densitometry of the femurs of 12-week-old male mice administered vehicle or LF at 30 or $300 \mathrm{mg} / \mathrm{kg} / \mathrm{day}$ with or without DEX. Cancellous BMC; A, cancellous BMD; $\mathrm{B}$ calculated by LaTheta software. Values are expressed as means $\pm \mathrm{SEM} ; \mathrm{n}=12$ mice per group. \#\#, $P<0.01$ and $\#, P<0.05$ significantly different from the control group, $P<0.05$, significantly different from the DEX-treated group.

A

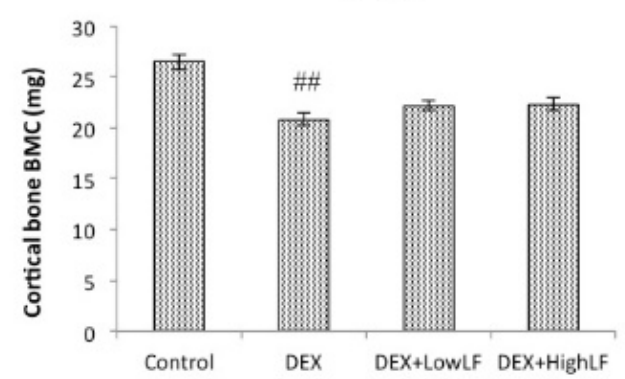

B

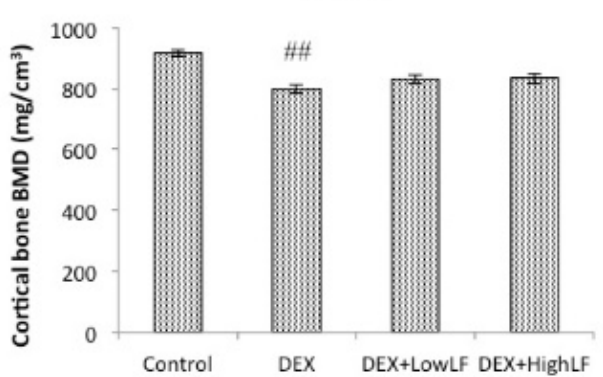

Figure 4. Effects of the administration of LF on cortical BMC and BMD in mice.

CT-based bone densitometry of the femurs of 12 -week-old male mice administered vehicle or LF at 30 or $300 \mathrm{mg} / \mathrm{kg} / \mathrm{day}$ with or without DEX. Cortical BMC; A, cortical BMD; B calculated by LaTheta software. Values are expressed as means \pm SEM; $\mathrm{n}=12$ mice per group. \#\#, $P<0.01$ and $\#, P<0.05$ significantly different from the control group, $P<0.05$, significantly different from the DEX-treated group.
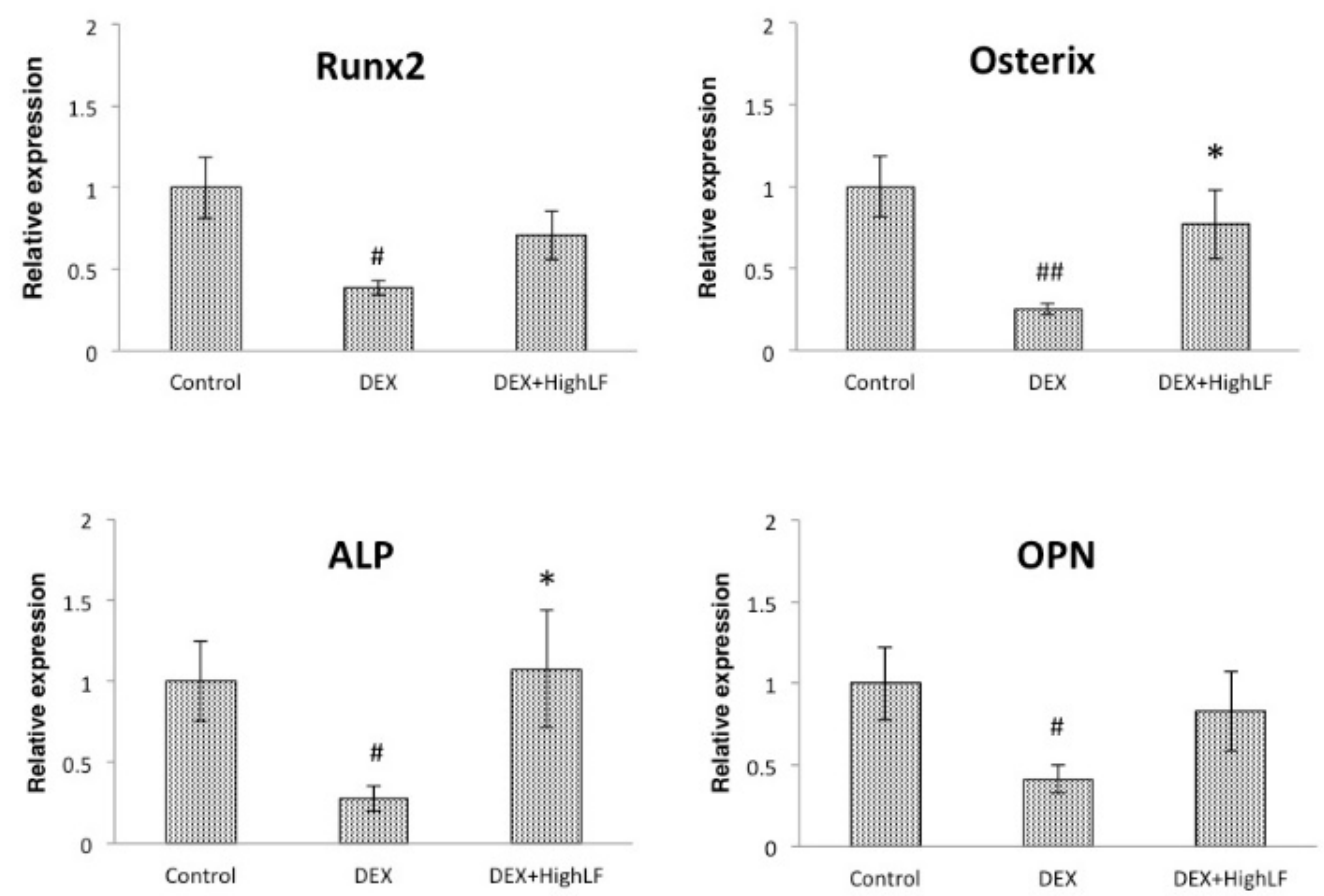

Figure 5. Effects of the administration of LF on osteoblast-related gene expression in cancellous bone.

Effects of the systemic administration of LF on Runx2, Osx, ALP, and OPN mRNA expression in cancellous bone. Total RNA was isolated from the distal region of the femur of 12-weekold male mice administered saline or LF (Bar: black) with or without DEX, followed by the assessment of Runx2, Osx, ALP, and OPN mRNA levels by real-time qRT-PCR using specific primers. $\mathrm{n}=12$ mice per group. Values are expressed as means $\pm \mathrm{SEM}$. \#\#, $P<0.01$ and $\#, P<0.05$ significantly different from the control group, $P<0.05$, significantly different from the DEX-treated group. 


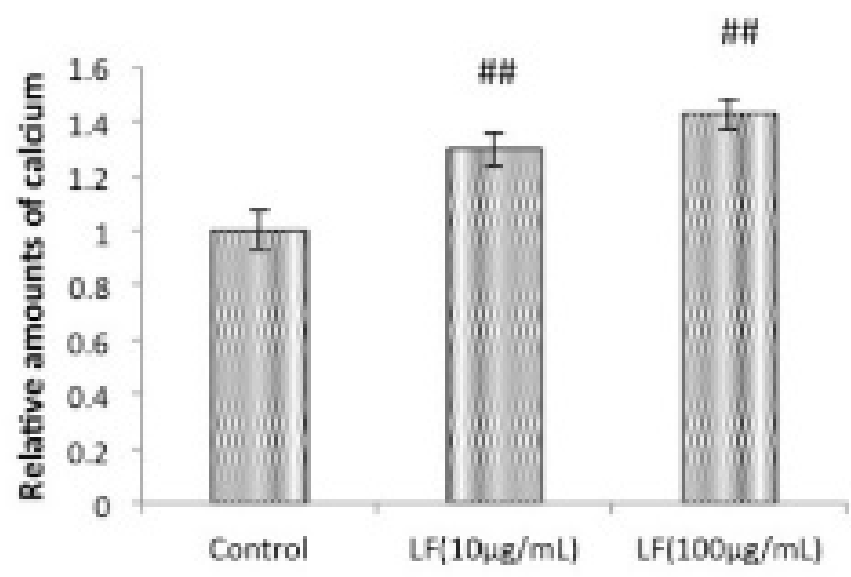

Figure 6. Effects of LF on Ca content in osteogenic MC3T3-E1 cells.

MC3T3-E1 cells were cultured for 21 days in the absence or presence of LF at the indicated concentrations, followed by the measurement of $\mathrm{Ca}$ deposition. Data are from 3 independent experiments. Values are expressed as means $\pm \operatorname{SEM}(\mathrm{n}=12)$. \#\#, $P<0.05$, significantly different from the control group.

\section{Competing Interests}

Financial support was provided by NRL Pharma, Inc., Kawasaki, Japan. There were no other relationships (employment, consultancy, patents, products in development, or marketed products) between the authors and NRL Pharma, Inc.

\section{References}

1. Rhen T, Cidlowski JA (2005) Anti-inflammatory action of glucocorticoids -new mechanisms for old drugs. $N$ Engl J Med 353: 1711-1723.

2. Strehl C, Buttgereit F (2013) Optimized glucocorticoid therapy: teaching old drugs new tricks. Mol Cell Endocrinol 380: 32-40. [Crossref]

3. Barnes PJ (2006) How corticosteroids control inflammation: Quintiles Prize Lecture 2005. Br J Pharmacol 148: 245-254. [Crossref]

4. Buttgereit F, Doering G, Schaeffler A, Witte S, Sierakowski S, et al. (2008) Efficacy of modified-release versus standard prednisone to reduce duration of morning stiffness of the joints in rheumatoid arthritis (CAPRA-1): a double-blind, randomised controlled trial. Lancet 371: 205-214. [Crossref]

5. Sambrook P, Birmingham J, Kempler S, Kelly P, Eberl S, et al. (1990) Corticosteroid effects on proximal femur bone loss. J Bone Miner Res 5: 1211-1216. [Crossref]

6. Henneicke H, Gasparini SJ, Brennan-Speranza TC, Zhou H, Seibel MJ (2014) Glucocorticoids and bone: local effects and systemic implications. Trends Endocrinol Metab 25: 197-211. [Crossref]

7. Kuo T, Harris CA, Wang JC (2013) Metabolic functions of glucocorticoid receptor in skeletal muscle. Mol Cell Endocrinol 380: 79-88. [Crossref]

8. Sivagurunathan S, Muir MM, Brennan TC, Seale JP, Mason RS (2005) Influence of glucocorticoids on human osteoclast generation and activity. $J$ Bone Miner Res 20 : 390-398. [Crossref]

9. Weinstein RS (2011) Clinical practice. Glucocorticoid-induced bone disease. $N$ Engl J Med 365: 62-70. [Crossref]

10. Henneicke H, Herrmann M, Kalak R, Brennan-Speranza TC, Heinevetter U, et al. (2011) Corticosterone selectively targets endo-cortical surfaces by an osteoblastdependent mechanism. Bone 49: 733-742. [Crossref]

11. O’Brien CA, Jia D, Plotkin LI, Bellido T, Powers CC, et al. (2004) Glucocorticoids act directly on osteoblasts and osteocytes to induce their apoptosis and reduce bone formation and strength. Endocrinology 145: 1835-1841. [Crossref]

12. Komori T (2016) Glucocorticoid Signaling and Bone Biology. Horm Metab Res 48: 755-763. [Crossref]

13. Tomita M, Wakabayashi H, Yamauchi K, Teraguchi S, Hayasawa H (2002) Bovine lactoferrin and lactoferricin derived from milk: production and applications. Biochem Cell Biol 80: 109-112. [Crossref]
14. Tomita M, Wakabayashi H, Shin K, Yamauchi K, Yaeshima T, et al. (2009) Twenty-five years of research on bovine lactoferrin applications. Biochimie 91: 52-57. [Crossref]

15. Ward PP, Mendoza-Meneses M, Cunningham GA, Conneely OM (2003) Iron status in mice carrying a targeted disruption of lactoferrin. Mol Cell Biol 23: 178-185.

16. Kanwar JR, Roy K, Patel Y, Zhou SF, Singh MR, et al. (2015) Multifunctional iron bound lactoferrin and nanomedicinal approaches to enhance its bioactive functions. Molecules 20: 9703-9731. [Crossref]

17. Cornish J, Callon KE, Naot D, Palmano KP, Banovic T, et al. (2004) Lactoferrin is a potent regulator of bone cell activity and increases bone formation in vivo. Endocrinology 145: 4366-4374. [Crossref]

18. Naot D, Chhana A, Matthews BG, Callon KE, Tong PC, et al. (2011) Molecular mechanisms involved in the mitogenic effect of lactoferrin in osteoblasts. Bone 49: 217-224. [Crossref]

19. Lorget F, Clough J, Oliveira M, Daury MC, Sabokbar A, et al. (2002) Lactoferrin reduces in vitro osteoclast differentiation and resorbing activity. Biochem Biophys Res Commun 296: 261-266. [Crossref]

20. Guo HY, Jiang L, Ibrahim SA, Zhang L, Zhang H, et al. (2009) Orally administered lactoferrin preserves bone mass and microarchitecture in ovariectomized rats. $J$ Nutr 139: 958-964. [Crossref]

21. Blais A, Malet A, Mikogami T, Martin-Rouas C, Tomé D (2009) Oral bovine lactoferrin improves bone status of ovariectomized mice. Am J Physiol Endocrinol Metab 296: E1281-E1288. [Crossref]

22. Izumo N, Ishibashi Y, Ohba M, Morikawa T, Manabe T (2012) Decreased voluntary activity and amygdala levels of serotonin and dopamine in ovariectomized rats. Behav Brain Res 227: 1-6. [Crossref]

23. Kanda J, Izumo N, Kobayashi Y, Onodera K, Shimakura T, et al. (2017) Effects of the Antiepileptic Drugs Phenytoin, Gabapentin, and Levetiracetam on Bone Strength, Bone Mass, and Bone Turnover in Rats. Biol Pharm Bull 40: 1934-1940. [Crossref]

24. Fujita T, Fukuyama R, Izumo N, Hirai T, Meguro T, et al. (2001) Transactivation of core binding factor alphal as a basic mechanism to trigger parathyroid hormoneinduced osteogenesis. Jpn J Pharmacol 86: 405-416. [Crossref]

25. Yao W, Cheng Z, Pham A, Busse C, Zimmermann EA, et al. (2008) Glucocorticoidinduced bone loss in mice can be reversed by the actions of parathyroid hormone and risedronate on different pathways for bone formation and mineralization. Arthritis Rheum 58: 3485-3497. [Crossref]

26. Balooch G, Yao W, Ager JW, Balooch M, Nalla RK, et al. (2007) The aminobisphosphonate risedronate preserves localized mineral and material properties of bone in the presence of glucocorticoids. Arthritis Rheum 56: 3726-3737. [Crossref]

27. Reid DM, Devogelaer JP, Saag K, Roux C, Lau CS, et al. (2009) Zoledronic acid and risedronate in the prevention and treatment of glucocorticoid-induced osteoporosis (HORIZON): a multicentre, double-blind, double-dummy, randomised controlled trial. Lancet 373: 1253-1263. [Crossref]

28. Devogelaer JP, Sambrook P, Reid DM, Goemaere S, Ish-Shalom S, et al. (2013) Effect on bone turnover markers of once-yearly intravenous infusion of zoledronic acid versus daily oral risedronate in patients treated with glucocorticoids. Rheumatology (Oxford) 52: 1058-1069. [Crossref]

29. Gluer CC, Marin F, Ringe JD, Hawkins F, Moricke R, et al. (2013) Comparative effects of teriparatide and risedronate in glucocorticoid-induced osteoporosis in men: 18-month results of the EuroGIOPs trial. J Bone Miner Res 28: 1355-1368. [Crossref]

30. Saag KG, Zanchetta JR, Devogelaer JP, Adler RA, Eastell R, et al. (2009) Effects of teriparatide versus alendronate for treating glucocorticoid-induced osteoporosis: thirtysix-month results of a randomized, double-blind, controlled trial. Arthritis Rheum 60: 3346-3355. [Crossref]

31. Zhang W, Guo H, Jing H, Li Y, Wang X, et al. (2014) Lactoferrin stimulates osteoblast differentiation through PKA and $\mathrm{p} 38$ pathways independent of lactoferrin's receptor LRP1. J Bone Miner Res 29: 1232-1243.

Copyright: (C2018 Izumo N. This is an open-access article distributed under the terms of the Creative Commons Attribution License, which permits unrestricted use, distribution, and reproduction in any medium, provided the original author and source are credited. 